TITLE:

\title{
Helicobacter pylori-induced activation-induced cytidine deaminase expression and carcinogenesis.
}

\author{
$\operatorname{AUTHOR}(\mathrm{S})$ :
}

Marusawa, Hiroyuki; Chiba, Tsutomu

\section{CITATION:}

Marusawa, Hiroyuki ... [et al]. Helicobacter pylori-induced activation-induced cytidine deaminase expression and carcinogenesis.. Current opinion in immunology 2010, 22(4): 442-447

\section{ISSUE DATE:}

2010-08

URL:

http://hdl.handle.net/2433/128867

\section{RIGHT:}

(C) 2010 Elsevier Ltd; この論文は出版社版でありません。引用の際には 出版社版をご確認ご利用ください。; This is not the published version. Please cite only the published version. 


\title{
Helicobacter pylori-induced AID expression and carcinogenesis.
}

Hiroyuki Marusawa* and Tsutomu Chiba.

\author{
Address \\ Department of Gastroenterology and Hepatology, \\ Graduate School of Medicine, Kyoto University \\ 54 Kawara-cho, Shogoin, Sakyo-ku, \\ Kyoto 606-8507, Japan. \\ *Corresponding Author: Hiroyuki Marusawa \\ E-mail:maru@kuhp.kyoto-u.ac.jp
}




\section{Summary of recent advances}

Tumorigenesis is a multistep process in which the accumulation of genetic alterations drives the transformation of normal cells into malignant derivatives. Activation-induced cytidine deaminase (AID) contributes to immune system diversity by inducing somatic hypermutations and class-switch recombinations of human immunoglobulin genes. The mutagenic activity of AID, however, can also induce genetic changes in various genes and may lead to the development of cancer. Helicobacter pylori, a class 1 carcinogen for human gastric cancer, affects AID expression by two different mechanisms, introduction of bacterial virulence factors into host cells and induction of inflammatory responses, thereby contributing to the accumulation of mutations in tumor-related genes. Aberrant AID activity may therefore be a novel link between infection and carcinogenesis. 


\section{Introduction}

Helicobacter pylori (H.pylori) is a gram-negative, spiral-shaped bacterium colonized in human populations for more than 58,000 years [1]. H.pylori infection is involved in the development of several human diseases, including gastro-duodenal ulcers, gastric cancer, and mucosa-associated lymphoid tissue (MALT) lymphoma of the stomach. H.pylori strains exhibit a high level of genetic diversity, and a striking difference among strains is the presence or absence of a 40-kb DNA segment, termed the cag pathogenicity island (PAI). The risk for developing H.pylori infection-mediated gastric disorders is closely associated with the strain [2]. The risk of developing gastric cancer is higher in patients infected with cagPAI-positive H.pylori compared with cagPAI-negative H.pylori [3,4], but how H.pylori infection contributes to gastric carcinogenesis remained unknown. Genetic changes in tumor-related genes are essential in the malignant transformation that leads to cancer cell development. How the intra-gastric residential bacteria induce the genetic changes required for tumorigenesis in host gastric epithelial cells is unclear, since the extracellular habitant H.pylori cannot directly access host genomic DNA located in the nucleus of gastric epithelial cells. Recent studies, however, revealed that cagPAI-positive H.pylori manipulates the host nucleotide editing enzymes to induce mutagenesis in human DNA sequences of the gastric epithelium [5].

\section{Novel mechanism of active mutagenesis achieved by nucleotide editing enzymes.}

Genetic changes in tumor-related genes are essential for malignant transformation in cancer cell development. Mechanisms that account for genetic changes required for tumorigenesis are unknown, except for defects in the DNA repair system that are observed in certain human cancers. Several enzymes that induce nucleotide alterations were recently identified, providing a new avenue for understanding the mutagenesis mechanism. The apolipoprotein B mRNA editing 
enzyme catalytic polypeptide (APOBEC) family comprises nucleotide editing enzymes that insert nucleotide alterations in target DNA or RNA through cytidine deamination [6]. The human APOBEC family consists of APOBEC1, -2, -3A, -3B, -3C, -3DE, -3F, -3G, -3H, -4, and activation-induced cytidine deaminase (AID), and contributes to producing various favorable physiologic outcomes by modifying target gene sequences. For example, APOBEC1 participates in lipid metabolism through deaminating a specific cytidine to uridine in the Apo-B mRNA, resulting in the formation of a termination codon, which leads to the production of a half-length genomically-encoded Apo-B100. APOBEC3G is an anti-viral molecule that induces hypermutation in viral DNA sequences and acts as a host defense factor against viruses such as HIV-1. Although the majority of APOBEC family members exhibit mutagenic activity against human RNA or exogenous viral genomes, only AID has the ability to induce nucleotide alterations and double-strand DNA breaks in human genomic sequences. Under physiologic conditions, AID is expressed in germinal center B-cells and induces somatic hypermutation and class-switch recombination of immunoglobulin genes, thereby amplifying immune system diversity[7]. In sharp contrast to the favorable role of AID in the immune system, excessive AID activity might affect non-immunoglobulin genes, including tumor-related genes in non-lymphoid cells [8].

\section{CagPAI-positive H.pylori induces aberrant AID expression in gastric epithelial cells.}

AID can alter host genomic information, but there are safeguard mechanisms that restrict its potential tumorigenic activity, including post-transcriptional regulation by microRNA [9-11], post-translational modification by protein phosphorylation or ubuiquitination [12-14], and regulation of subcellular localization [15-18]. Restriction of AID expression is also an important regulatory system that minimizes the aberrant mutagenic activity of AID. AID gene 
transcription is restricted mainly to activated germinal center B lymphocytes where editing of the immunoglobulin gene is required[19,20], while AID expression is not detected in normal epithelial cells under physiologic conditions. How then is AID expressed in epithelial cells under pathologic conditions, especially where the tumorigenic risk is unusually high? Strikingly, endogenous AID is expressed in the epithelial cells of H.pylori -infected stomach. Gastric epithelial cells and some infiltrating lymphocytes are immunoreactive for AID protein expression in the majority of chronic gastritis tissues infected with cagPAI-positive H.pylori [21]. Moreover, eradication of H.pylori infection by antibiotics substantially decreases AID protein expression in gastric mucosa. These findings suggest that cagPAI-positive H.pylori somehow upregulates AID protein in the gastric epithelium of the infected host.

CagPAI contain approximately 30 putative genes encoding various bacterial proteins such as cytotoxin-associated gene A (cagA) [22]. CagPAI-positive H.pylori introduces several bacterial virulence factors into gastric epithelial cells through a type-IV secretion apparatus, and cagPAI-positive H.pylori -derived peptidoglycans introduced into the host cells has been shown to be responsible for activating the transcription factor NF-kB [23]. The AID promoter region also includes sites for several transcription factors, such as NF-кB, STAT6, HoxC4, Sp1, Sp3, and Pax5 [24-27], and AID expression in B lymphocytes is induced in response to NF- $\mathrm{B}$ activation through CD40 ligand signaling [28]. Together, these findings suggest that cagPAI-positive H.pylori induces AID expression via NF-אB activation by introducing bacterial virulence factors, and that the proinflammatory response caused by H.pylori infection also triggers AID expression via the activation of $\mathrm{NF}-\mathrm{\kappa B}$ in gastric epithelium, because proinflammatory cytokines such as tumor necrosis factor (TNF)- $\alpha$ and IL-1 $\beta$ can induce NF- $\kappa B$ activation in various types of cells. These hypotheses are supported by in vitro analyses showing 
that AID expression is induced in response to cagPAI-positive H.pylori infection or stimulation with the proinflammatory cytokine TNF- $\alpha$ via NF- $\kappa B$ signaling in cultured human gastric epithelial cells [21]. Based on the clinical course of H.pylori-infected individuals, both bacterial factors that are introduced into epithelial cells and the inflammatory response against H.pylori infection would be responsible for aberrant AID expression in gastric epithelium (Figure 1), and the direct action of the bacterial virulence factors contributes to activate AID in the early stage of H.pylori infection when the number of bacteria is high. In the late phase of chronic gastritis, when gastric atrophy has progressed and the number of H.pylori is decreased, the proinflammatory cytokine plays a central role in causing the constitutive expression of AID in gastric epithelial cells.

\section{AID induces DNA mutations in tumor-related genes in gastric epithelial cells.}

The target of AID-mediated genotoxic effects is not restricted to immunoglobulin genes and several non-immunoglobulin genes are also targeted by AID in lymphocytes. Approximately 25\% of expressed non-immunoglobulin genes analyzed, including Bcl6 and Cd83, accumulated AID-mediated mutations in germinal B cells [29]. Moreover, AID produces double-strand DNA breaks throughout the genome, including c-myc in B cells [30,31]. The impact of AID expression in non-lymphoid gastrointestinal epithelial cells was clarified using mouse model with constitutive and ubiquitous AID expression. AID transgenic mice accumulated somatic mutations in various tumor-related genes and developed tumors in both lymphoid and non-lymphoid tissues [32,33]. The tumors developed in the epithelial organs of AID transgenic mice included lung, liver, and gastric cancers.

The findings that AID mutagenic activity results in stomach cancer led us to speculate that 
H.pylori infection in association with aberrant AID expression contributes to human carcinogenesis via the accumulation of genetic alterations in gastric epithelial cells[21]. In in vitro-cultured gastric epithelial cells, cagPAI-positive H.pylori infection led to somatic mutations in the tumor-suppressor TP53 gene. The number of nucleotide alterations observed in H.pylori-infected cells was significantly reduced by knockdown of endogenous AID, indicating that the somatic mutations in the TP53 gene in cells infected with cagPAI-positive H.pylori were due to the induction of endogenous AID expression in gastric cells. In wild-type mice, oral infection with cagPAI-positive H.pylori upregulated AID protein expression. Moreover, nucleotide alterations emerge in the TP53 gene in stomach tissues after oral H.pylori infection in wild-type mice. These findings strongly suggest that H.pylori infection causes accumulation of somatic mutations in tumor-related genes such as TP53 through aberrant upregulation of AID in gastric epithelial cells.

\section{H.pylori-associated lymphoid tumorigenesis and AID expression}

Low-grade lymphomas originating from MALT develop in the stomach, salivary and thyroid glands, bronchi, and small intestine, and are classified as MALT lymphoma [34,35]. The acquisition of MALT is induced prior to the development of lymphoma as a response to a persistent antigenic stimulation [36]. The development of gastric MALT lymphoma, a representative gastric lymphoma, is strongly associated with H.pylori infection [37]. The seroprevalence of H.pylori is higher in patients with gastric MALT lymphomas than in control patients without MALT lymphoma [38], and eradication of H.pylori leads to complete regression of the lymphoma in nearly $80 \%$ of patients with early-stage disease $[39,40]$. On the other hand, several studies have aimed to clarify the role of AID in the development of MALT lymphoma, 
because AID is required for the development of germinal center-derived non-Hodgkin's lymphomas [41,42]. AID mRNA was, however, expressed in only some extranodal marginal zone B-cell MALT lymphomas [41]. More recent studies demonstrate that neoplastic marginal zone B cells did not express detectable AID, whereas AID expression was confined to reactive areas within MALT lymphomas [43,44]. In addition to the low frequency of AID upregulation in MALT lymphoma tissues, it remains unknown whether H.pylori infection enhances the aberrant mutagenic activity of AID in gastric B-cells. Further analyses are required to determine the role of AID in the development of H.pylori-associated MALT lymphomas.

\section{Conclusions}

The discovery of AID was a seminal finding that greatly advanced our understanding of the molecular mechanisms involved in immunoglobulin diversification [45]. Now, AID is central to our understanding of how inflammation and infection underlie the genetic alterations required for carcinogenesis in epithelial cells [46]. Indeed, proinflammatory cytokine induction of AID expression via the NF- $\kappa \mathrm{B}$ pathway is not limited to gastric epithelial cells. AID expression is mediated by the inflammatory response in a variety of epithelial cells, including human hepatocytes [47,48], and biliary[49] and colonic epithelial cells[50]. Aberrant AID expression in these gastrointestinal organs results in somatic mutations in various tumor-related genes. Thus, AID may have a central role in genetic susceptibility to mutagenesis, which leads to cancers in these gastrointestinal tissues upon exposure to certain inflammation or infection (Figure 2).

A characteristic of H.pylori-associated gastric cancer is multicentric tumor development. Patients with a history of H.pylori-related gastric cancer are at high risk for subsequent development of gastric cancers[51], suggesting that each epithelial cell of the H.pylori-infected 
stomach possesses sufficient genetic damage for malignant transformation. Efficient strategies to restrict aberrant AID activity might help to prevent carcinogenesis in gastric epithelial cells inflamed by H.pylori infection. 


\section{References}

1. Linz B, Balloux F, Moodley Y, Manica A, Liu H, Roumagnac P, Falush D, Stamer C, Prugnolle F, van der Merwe SW, et al.: An African origin for the intimate association between humans and Helicobacter pylori. Nature 2007, 445:915-918.

2. Cover TL, Blaser MJ: Helicobacter pylori in health and disease. Gastroenterology 2009, 136:1863-1873.

3. Huang JQ, Zheng GF, Sumanac K, Irvine EJ, Hunt RH: Meta-analysis of the relationship between cagA seropositivity and gastric cancer. Gastroenterology 2003, 125:1636-1644.

4. Basso D, Zambon CF, Letley DP, Stranges A, Marchet A, Rhead JL, Schiavon S, Guariso G, Ceroti M, Nitti D, et al.: Clinical relevance of Helicobacter pylori cagA and vacA gene polymorphisms. Gastroenterology 2008, 135:91-99.

5. Chiba T, Marusawa H: A novel mechanism for inflammation-associated carcinogenesis; an important role of activation-induced cytidine deaminase (AID) in mutation induction. $J$ Mol Med 2009, 87:1023-1027.

6. Conticello SG: The AID/APOBEC family of nucleic acid mutators. Genome Biol 2008, 9:229.

7. Shivarov V, Shinkura R, Doi T, Begum NA, Nagaoka H, Okazaki IM, Ito S, Nonaka T, Kinoshita K, Honjo T: Molecular mechanism for generation of antibody memory. Philos Trans $R$ Soc Lond B Biol Sci 2009, 364:569-575.

8. Kinoshita K, Nonaka T: The dark side of activation-induced cytidine deaminase: relationship with leukemia and beyond. Int $J$ Hematol 2006, 83:201-207.

9. Dorsett Y, McBride KM, Jankovic M, Gazumyan A, Thai TH, Robbiani DF, Di Virgilio M, San-Martin BR, Heidkamp G, Schwickert TA, et al.: MicroRNA-155 suppresses activation-induced cytidine deaminase-mediated Myc-Igh translocation. Immunity 2008, 28:630-638.

10. Teng G, Hakimpour P, Landgraf P, Rice A, Tuschl T, Casellas R, Papavasiliou FN: MicroRNA-155 is a negative regulator of activation-induced cytidine deaminase. Immunity 2008, 28:621-629.

*11. de Yebenes VG, Belver L, Pisano DG, Gonzalez S, Villasante A, Croce C, He L, Ramiro AR: miR-181b negatively regulates activation-induced cytidine deaminase in B cells. J Exp Med 2008, 205:2199-2206.

*References 9 and 10* demonstrate microRNA-155 (miR-155) is upregulated in B lymphocytes undergoing class-switch recombination and regulate the transcription of AID by targeting the 3' untranslated region of the AID mRNA, suggesting the possible role of miR-155 as a tumor suppressor by inhibiting the genotoxic effect of AID. Similarly, reference 11 showed the negative regulation of AID transcription by another microRNA-181b.

12. McBride KM, Gazumyan A, Woo EM, Schwickert TA, Chait BT, Nussenzweig MC: Regulation of class switch recombination and somatic mutation by AID phosphorylation. J Exp Med 2008, 
205:2585-2594.

13. Cheng HL, Vuong BQ, Basu U, Franklin A, Schwer B, Astarita J, Phan RT, Datta A, Manis J, Alt FW, et al.: Integrity of the AID serine-38 phosphorylation site is critical for class switch recombination and somatic hypermutation in mice. Proc Natl Acad Sci U SA 2009, 106:2717-2722.

14. Aoufouchi S, Faili A, Zober C, D'Orlando O, Weller S, Weill JC, Reynaud CA: Proteasomal degradation restricts the nuclear lifespan of AID. $J$ Exp Med 2008, 205:1357-1368.

15. Patenaude AM, Orthwein A, Hu Y, Campo VA, Kavli B, Buschiazzo A, Di Noia JM: Active nuclear import and cytoplasmic retention of activation-induced deaminase. Nat Struct Mol Biol 2009, 16:517-527.

16. Geisberger R, Rada C, Neuberger MS: The stability of AID and its function in class-switching are critically sensitive to the identity of its nuclear-export sequence. Proc Natl Acad Sci USA2009, 106:6736-6741.

17. Casellas R, Yamane A, Kovalchuk AL, Potter M: Restricting activation-induced cytidine deaminase tumorigenic activity in B lymphocytes. Immunology 2009, 126:316-328.

18. Ito S, Nagaoka H, Shinkura R, Begum N, Muramatsu M, Nakata M, Honjo T: Activation-induced cytidine deaminase shuttles between nucleus and cytoplasm like apolipoprotein B mRNA editing catalytic polypeptide 1. Proc Natl Acad Sci U S A 2004, 101:1975-1980.

19. Muramatsu M, Sankaranand VS, Anant S, Sugai M, Kinoshita K, Davidson NO, Honjo T: Specific expression of activation-induced cytidine deaminase (AID), a novel member of the RNA-editing deaminase family in germinal center B cells. J Biol Chem 1999, 274:18470-18476.

20. Muto T, Muramatsu M, Taniwaki M, Kinoshita K, Honjo T: Isolation, tissue distribution, and chromosomal localization of the human activation-induced cytidine deaminase (AID) gene.

Genomics 2000, 68:85-88.

21. Matsumoto Y, Marusawa H, Kinoshita K, Endo Y, Kou T, Morisawa T, Azuma T, Okazaki IM, Honjo T, Chiba T: Helicobacter pylori infection triggers aberrant expression of activation-induced cytidine deaminase in gastric epithelium. Nat Med 2007, 13:470-476.

22. Hatakeyama M: Helicobacter pylori and gastric carcinogenesis. J Gastroenterol 2009, 44:239-248.

23. Viala J, Chaput C, Boneca IG, Cardona A, Girardin SE, Moran AP, Athman R, Memet S, Huerre MR, Coyle AJ, et al.: Nod1 responds to peptidoglycan delivered by the Helicobacter pylori cag pathogenicity island. Nat Immunol 2004, 5:1166-1174.

24. Crouch EE, Li Z, Takizawa M, Fichtner-Feigl S, Gourzi P, Montano C, Feigenbaum L, Wilson P, Janz S, Papavasiliou FN, et al.: Regulation of AID expression in the immune response. J Exp Med 2007, 204:1145-1156.

25. Yadav A, Olaru A, Saltis M, Setren A, Cerny J, Livak F: Identification of a ubiquitously active promoter of the murine activation-induced cytidine deaminase (AICDA) gene. Mol Immunol 2006, 43:529-541. 
26. Park SR, Zan H, Pal Z, Zhang J, Al-Qahtani A, Pone EJ, Xu Z, Mai T, Casali P: HoxC4 binds to the promoter of the cytidine deaminase AID gene to induce AID expression, class-switch DNA recombination and somatic hypermutation. Nat Immunol 2009, 10:540-550.

27. Tran TH, Nakata M, Suzuki K, Begum NA, Shinkura R, Fagarasan S, Honjo T, Nagaoka H: B cell-specific and stimulation-responsive enhancers derepress Aicda by overcoming the effects of silencers. Nat Immunol 2010, 11:148-154.

28. Dedeoglu F, Horwitz B, Chaudhuri J, Alt FW, Geha RS: Induction of activation-induced cytidine deaminase gene expression by IL-4 and CD40 ligation is dependent on STAT6 and NFkappaB. Int Immunol 2004, 16:395-404.

**29. Liu M, Duke JL, Richter DJ, Vinuesa CG, Goodnow CC, Kleinstein SH, Schatz DG: Two levels of protection for the B cell genome during somatic hypermutation. Nature 2008, 451:841-845.

**By extensive sequencing of murine B cell genes, the authors demonstrate that AID acts broadly on the genome and approximately 25\% of expressed genes analyzed in this study accumulated mutations possibly induced by AID activity in germinal centre B cells.

30. Robbiani DF, Bothmer A, Callen E, Reina-San-Martin B, Dorsett Y, Difilippantonio S, Bolland DJ, Chen HT, Corcoran AE, Nussenzweig A, et al.: AID is required for the chromosomal breaks in c-myc that lead to c-myc/IgH translocations. Cell 2008, 135:1028-1038.

*31. Robbiani DF, Bunting S, Feldhahn N, Bothmer A, Camps J, Deroubaix S, McBride KM, Klein IA, Stone G, Eisenreich TR, et al.: AID produces DNA double-strand breaks in non-Ig genes and mature B cell lymphomas with reciprocal chromosome translocations. Mol Cell 2009, 36:631-641.

*Demonstration of the capacity of AID to produce paired DNA double-strand break throughout the genome which can lead to lymphoma-associated chromosome translocation in mature B cells.

32. Okazaki IM, Hiai H, Kakazu N, Yamada S, Muramatsu M, Kinoshita K, Honjo T: Constitutive expression of AID leads to tumorigenesis. J Exp Med 2003, 197:1173-1181.

33. Morisawa T, Marusawa H, Ueda Y, Iwai A, Okazaki IM, Honjo T, Chiba T: Organ-specific profiles of genetic changes in cancers caused by activation-induced cytidine deaminase expression. Int $J$ Cancer 2008, 123:2735-2740.

34. Isaacson P, Wright DH: Malignant lymphoma of mucosa-associated lymphoid tissue. A distinctive type of B-cell lymphoma. Cancer 1983, 52:1410-1416.

35. Zucca E, Bertoni F, Roggero E, Cavalli F: The gastric marginal zone B-cell lymphoma of MALT type. Blood 2000, 96:410-419.

36. Suarez F, Lortholary O, Hermine O, Lecuit M: Infection-associated lymphomas derived from marginal zone B cells: a model of antigen-driven lymphoproliferation. Blood 2006, 107:3034-3044.

37. Isaacson PG, Du MQ: MALT lymphoma: from morphology to molecules. Nat Rev Cancer 2004, 4:644-653. 
38. Parsonnet J, Hansen S, Rodriguez L, Gelb AB, Warnke RA, Jellum E, Orentreich N, Vogelman JH, Friedman GD: Helicobacter pylori infection and gastric lymphoma. N Engl J Med 1994, 330:1267-1271.

39. Zullo A, Hassan C, Andriani A, Cristofari F, De Francesco V, Ierardi E, Tomao S, Morini S, Vaira

D: Eradication therapy for Helicobacter pylori in patients with gastric MALT lymphoma: a pooled data analysis. Am J Gastroenterol 2009, 104:1932-1937; quiz 1938.

40. Wotherspoon AC, Doglioni C, Diss TC, Pan L, Moschini A, de Boni M, Isaacson PG: Regression of primary low-grade B-cell gastric lymphoma of mucosa-associated lymphoid tissue type after eradication of Helicobacter pylori. Lancet 1993, 342:575-577.

41. Greeve J, Philipsen A, Krause K, Klapper W, Heidorn K, Castle BE, Janda J, Marcu KB, Parwaresch R: Expression of activation-induced cytidine deaminase in human B-cell non-Hodgkin lymphomas. Blood 2003, 101:3574-3580.

*42. Pasqualucci L, Bhagat G, Jankovic M, Compagno M, Smith P, Muramatsu M, Honjo T, Morse HC, 3rd, Nussenzweig MC, Dalla-Favera R: AID is required for germinal center-derived lymphomagenesis. Nat Genet 2008, 40:108-112.

*By crossing the mouse model of B cell lymphoma with the AID deficient mouse, the authors showed that AID deficiency prevents Bcl6-dependent, germinal center-derived B cell lymphomas.

43. Bombardieri M, Barone F, Humby F, Kelly S, McGurk M, Morgan P, Challacombe S, De Vita S, Valesini G, Spencer J, et al.: Activation-induced cytidine deaminase expression in follicular dendritic cell networks and interfollicular large B cells supports functionality of ectopic lymphoid neogenesis in autoimmune sialoadenitis and MALT lymphoma in Sjogren's syndrome. J Immunol 2007, 179:4929-4938.

44. Deutsch AJ, Aigelsreiter A, Staber PB, Beham A, Linkesch W, Guelly C, Brezinschek RI, Fruhwirth M, Emberger W, Buettner M, et al.: MALT lymphoma and extranodal diffuse large B-cell lymphoma are targeted by aberrant somatic hypermutation. Blood 2007, 109:3500-3504.

45. Delker RK, Fugmann SD, Papavasiliou FN: A coming-of-age story: activation-induced cytidine deaminase turns 10. Nat Immunol 2009, 10:1147-1153.

46. Marusawa H: Aberrant AID expression and human cancer development. Int J Biochem Cell Biol 2008, 40:1399-1402.

47. Endo Y, Marusawa H, Kinoshita K, Morisawa T, Sakurai T, Okazaki IM, Watashi K, Shimotohno

K, Honjo T, Chiba T: Expression of activation-induced cytidine deaminase in human hepatocytes via NF-kappaB signaling. Oncogene 2007, 26:5587-5595.

**48. Takai A, Toyoshima T, Uemura M, Kitawaki Y, Marusawa H, Hiai H, Yamada S, Okazaki IM, Honjo T, Chiba T, et al.: A novel mouse model of hepatocarcinogenesis triggered by AID causing 
deleterious p53 mutations. Oncogene 2008.

**Pioneering study demonstrating the critical role of mutational accumulation in immature stem cells on the development of cancer cells. The authors show that constitutive AID expression in cells producing a marker of immature hepatocytes resulted in the appearance of hepatocellular carcinoma.

49. Komori J, Marusawa H, Machimoto T, Endo Y, Kinoshita K, Kou T, Haga H, Ikai I, Uemoto S, Chiba T: Activation-induced cytidine deaminase links bile duct inflammation to human cholangiocarcinoma. Hepatology 2008, 47:888-896.

*50. Endo Y, Marusawa H, Kou T, Nakase H, Fujii S, Fujimori T, Kinoshita K, Honjo T, Chiba T:

Activation-induced cytidine deaminase links between inflammation and the development of colitis-associated colorectal cancers. Gastroenterology 2008, 135:889-898, 898 e881-883.

*The authors show that AID expression in human colonic epithelial cells is induced in response to Th2-driven cytokines IL-4 and IL-13, which are activated in inflammatory bowel disease. This is the first study to provide the possible link between colonic inflammation, AID expression and colorectal cancer development.

51. Aoi T, Marusawa H, Sato T, Chiba T, Maruyama M: Risk of subsequent development of gastric cancer in patients with previous gastric epithelial neoplasia. Gut 2006, 55:588-589. 